\title{
AIR VELOCITY PROFILES IN AIR BLAST FREEZERS FILLED WITH BOXES OF FRUIT PULP MODELS
}

\begin{abstract}
J.V. Resende a, ABSTRACT and V. Silveira Jr. ${ }^{\mathbf{b}}$

${ }^{a}$ Universidade Federal de Lavras Departamento de Ciências Exatas Caixa Postal 37 Campus Universitário 37200-000, Lavras, Minas Gerais, Brasil jvresen@bol.com.br

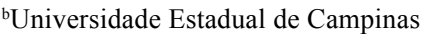
Caixa Postal 6121 Cid. Universitária Zeferino Vaz 13083-970, Campinas, São Paulo, Brasil vivaldo@ceres.fea.unicamp.br

The changes in the air velocities caused by the resistance for the air flow due to fruit pulp model packaged (100 grams) and conditioned in multi layers boxes during freezing process were evaluated and air flow rate were estimated using a method of treatment of the experimental data. The air velocities were measured before the air pass through the pillage of multi layer boxes in the air stream. For the measurements processing was used a non linear regression routine. Air flow rate measured by the present method resulted of the numerical integration of air velocities adjusted profile. Results presented a relative difference $10 \%$ higher than the standard average procedure, which consists in averaging the air velocity measurements performed at each point of the section. In the same fan operation conditions, the results shown for the 7 layers arrays of product in the boxes which the air velocity was $62 \%$ lower than the 3 layers arrays and $50.9 \%$ lower than the 5 layers arrays of product. These results were proportional to the bulk area for the air flow.

Keywords: air velocity profiles, freezers.
\end{abstract}

\section{INTRODUCTION}

Air is chosen as cooling agent in many situations, for example, in air blast freezers. The two main reasons for the use of air in refrigeration systems are: the low energy consumption to move it and to pass it by the product and the space distribution of the air velocity around of the product (Earle, 1985)

Another important question is the air distribution in relation to the chamber geometry and the flow path uniformity. Therefore, the air flow control is a critical point in the installation. In food freezing, the air velocity profile determines the efficiency and the homogeneity of the treatments that the product is being submitted. In equipment used in the food processing, the air flow is generally turbulent and transient. Due to strong variability of the air velocity in the space and time, its measure is considered as a great problem, producing results not very accurate and indispensable in the air flow rate determination and heat transfer calculations.

Mirade and Daudin (1998); Peyrin et al. (1995); Ower and Pankhurst (1977) cited difficulties related to the air velocities in the plant. Between these they are: (1) the air flow is unstable; (2) the air flow route is strongly influenced by the object presence, and, in the neighborhoods of the measure point, this is more difficult of being evaluated; (3) the air temperature is very different of that used by the manufacturer to calibrate the device that frequently is around $20^{\circ} \mathrm{C}$.
Based in the mentioned difficulties above, this work has as objective: (i) the development of an air velocity measure methodology in the freezing chamber containing product conditioned in boxes, searching to eliminate the difficulties and error sources inherent to the air flow and, (ii) the analysis of the air velocity profile and air flow rate in the freezing chamber and the influence of the product amount in the boxes on the resistance to the air flow.

\section{MATERIALS AND METHODS}

\section{Location of the measure points of the air velocity in the freezing chamber}

In the door of the horizontal freezing chamber were made ten holes, distributed in two groups of five holes spaced in intervals of $0.10 \mathrm{~m}$ in vertical alignment (Fig.1). Probe for the air velocity measurement was introduced by these apertures, being the measure points, fixed for each point of the section height varying in equal intervals of $0.025 \mathrm{~m}$ the depth with that the probe is inserted in the chamber. The objective was to collect air velocity readings in multiple points along of the perpendicular section to the air flow before the pass by the product.

\section{Experimental Procedure}

After the operational conditions establishment 
of the equipment, a piling up of three boxes of plastic material containing the samples packages (100 grams) of fruit pulp models (k-carrageenan, $0.5 \%+$ sucrose $10 \%$ ) in arrays of 7,5 and 3 layers; were placed in the freezing chamber. To prevent the preferential channels formation it was used, expanded polystyrene boards placed in the lateral sections of the boxes. The boards forced all the air to pass through the boxes with the product. The air velocity was established as a function of the product amount in each box, being the piling up the responsible obstacle for the resistance to the air flow in the chamber.

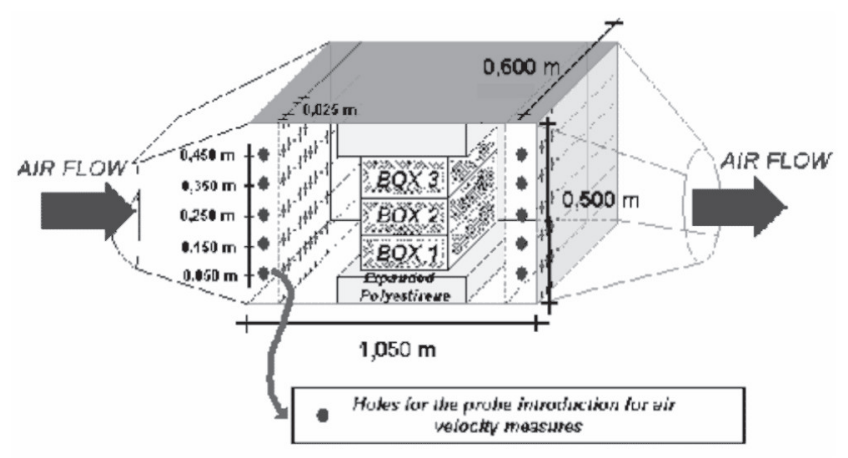

Figure 1. Position of probe used air velocity readings in the freezing chamber section.

The available area $\left(A_{E}\right)$ for the flow was evaluated by the following equation:

$$
A_{E}=A_{\text {Total }}-A_{\text {array }}
$$

The calculated values of $\mathrm{A}_{\mathrm{E}}, \mathrm{A}_{\text {array }}$, and $\mathrm{A}_{\text {Total }}$ for experiments with arrays of 7, 5 and 3 layers of product, as well as the boxes average dimensions and the individual packages are shown in Tab.1.

Table 1. Parameters used in the equation (1) for flow area evaluation.

\begin{tabular}{|c|c|c|c|c|}
\hline \multicolumn{5}{|c|}{ Dimensions of the samples (Average value) } \\
\hline & & Boxes & $\begin{array}{l}\text { Poly } \\
\text { bags }\end{array}$ & $\begin{array}{l}\text { hylene } \\
(100 \mathrm{~g})\end{array}$ \\
\hline \multicolumn{2}{|c|}{ Length (m) } & $\mathrm{D} 1=0.585$ & \multicolumn{2}{|c|}{$\mathrm{D} 4=0.1072$} \\
\hline \multicolumn{2}{|c|}{ Width (m) } & $\mathrm{D} 2=0.400$ & \multicolumn{2}{|c|}{ D5 $=0.0722$} \\
\hline \multicolumn{2}{|c|}{ Height (m) } & D3 $=0.125$ & D6 $=$ & 0.0160 \\
\hline \multicolumn{5}{|c|}{ Parameters used in Equation (1) } \\
\hline $\begin{array}{c}\mathrm{Cm} \\
\text { (layers) }\end{array}$ & $\begin{array}{c}A_{\text {Total }}=3 \times D 1 \times D 3 \\
\left(m^{2}\right)\end{array}$ & \multicolumn{2}{|c|}{$\begin{array}{c}\mathrm{A}_{\text {array }}=5 \times \mathrm{Cm}^{2} \times \mathrm{x} 4 \mathrm{xD6} 6 \\
\left(\mathrm{~m}^{2}\right)\end{array}$} & $\begin{array}{c}\mathrm{A}_{\mathrm{E}} \\
\left(\mathrm{m}^{2}\right)\end{array}$ \\
\hline 7 & 0.2194 & \multicolumn{2}{|c|}{0.1801} & 0.0393 \\
\hline 5 & 0.2194 & \multicolumn{2}{|c|}{0.1286} & 0.0907 \\
\hline 3 & 0.2194 & \multicolumn{2}{|c|}{0.0772} & 0.1422 \\
\hline
\end{tabular}

Air temperature was controlled using electric resistances, for a constant heat load. Factors considered were air temperatures (3 levels) and product amounts ( 3 levels) as shown in Tab. 2 .

\section{Air velocity measurements}

After the product loading and with the equipment in operation, the air velocity measure was made using a hot wire anemometer (TSI, USA, Model 8330-M). The readings were established in 115 points, spaced along of the chamber with three replications, resulting the 345 readings for each assay. The air velocity was measured in all the experiments (81 assays), resulting in 9 replications for each type of configuration (array of layers) and air temperature.

Table 2 - Factors and factor levels considered in the evaluation of the air velocity measures.

\begin{tabular}{|c|c|c|c|}
\hline \multirow{2}{*}{ Variable } & \multicolumn{3}{|c|}{ Levels } \\
\cline { 2 - 4 } & +1 & 0 & -1 \\
\hline $\begin{array}{c}\text { Air } \\
\text { temperature } \\
\left({ }^{\circ} \mathrm{C}\right)\end{array}$ & $\cong-30$ & $\cong-25$ & $\cong-20$ \\
\hline $\begin{array}{c}\text { Product } \\
\text { amount }\end{array}$ & 7 Layers/box & 5 Layers/box & 3 Layers/box \\
\hline
\end{tabular}

\section{Air velocity readings correction for low temperatures}

The measurement instrument used for the air velocity had temperature compensation, what means that, in a uniform flow, the output readings remain constant throughout a temperature band. The procedure for correction of the indicated air velocity by the instrument $\left(\mathrm{v}_{1}\right)$ for the real velocity $\left(\mathrm{v}_{2}\right)$ necessary for the temperature compensation from data of temperature and ambient pressure was considered by the instrument manufacturer (TSI Incorporated, 1997).

\section{Analyses of the air velocity in the freezing chamber section}

Analysis was made, tracing the air velocity profile in the chamber section, from the average of the readings made by thermoanemometer after the corrections. From the surface curves of the air velocity as function of the coordinates defined by the height $(\mathrm{x})$ and width (y) of the chamber section 
was obtained the response surface represented by the equation:

$$
\mathrm{v}=\mathrm{F}(\mathrm{x}, \mathrm{y})
$$

The response surfaces fit had been made by least squares using the TableCurve $3 \mathrm{D}^{\circledR}$ software that makes a scanning testing some equations and selecting the better surface fit obtained from the experimental points, with option of the selection to be made in the best correlation $\left(r^{2}\right)$, standard deviation or statistical F.

\section{Evaluation of the air flow rate in the freezing chamber}

Air flow rate was evaluated quantifying the volume under the response surface of the air velocities after adjust as described previously. This evaluation was made by numerical integration under the response surface by the resolution of the equation (3) shown to follow:

$$
\dot{V}=\int_{a}^{b} \int_{c}^{d} F(x, y) d y d x
$$

where $\mathrm{c} \leq \mathrm{x} \leq \mathrm{d}$ understands the referring interval to the input section height of the freezing chamber, being equal the $0.050 \leq \mathrm{x} \leq 0.450(\mathrm{~m})$, and $\mathrm{a} \leq \mathrm{y} \leq$ $\mathrm{b}$ mentions to the section width (depth), being equal $0.001 \leq \mathrm{y} \leq 0.600(\mathrm{~m})$.

The used methodology is the bidimensional numerical integration by the parabolic rule (or bidimensional Simpson rule) whose resolution was made through iterations applied to the following equation (4) (Hoerl et al., 1984):

$$
\begin{aligned}
& \int_{a}^{b} \int_{c}^{d} F(x, y) d x d y=\frac{h k}{9}\left[\left(F_{0,0}+4 F_{1,0}+2 F_{2,0}+4 F_{3,0}+2 F_{4,0}+\ldots+F_{m, 0}\right)+\right. \\
& 4\left(F_{0,1}+4 F_{1,1}+2 F_{2,1}+\ldots+F_{m, 1}\right)+2\left(F_{0,2}+4 F_{1,2}+2 F_{2,2}+\ldots+F_{m, 2}\right)+\ldots+ \\
& \left.\left(F_{0, n}+4 F_{1, n}+2 F_{2, n}+\ldots+F_{m, n}\right)\right]+E_{m, n}
\end{aligned}
$$

For the resolution of the equation (4), the interval $\mathrm{x}=[0.050 ; 0.450]$ was subdivided in $\mathrm{m}=80$ subintervals of size $\mathrm{h}=(\mathrm{d}-\mathrm{c}) / \mathrm{m}=0.005(\mathrm{~m})$ and the interval $\mathrm{y}=[0.001 ; 0.600]$ in $\mathrm{n}=120$ subintervals of size $\mathrm{k}=(\mathrm{b}-\mathrm{a}) / \mathrm{n}=0.005(\mathrm{~m})$. Considers the functions $\mathrm{F}_{1, \mathrm{j}}=\mathrm{F}\left(\mathrm{x}_{\mathrm{i}}, \mathrm{y}_{\mathrm{j}}\right)(\mathrm{m} / \mathrm{s})$ being $\mathrm{y}_{\mathrm{i}}=\mathrm{b}+\mathrm{ik}$ and $\mathrm{x}_{\mathrm{j}}=\mathrm{c}+\mathrm{jh}$.
The values of $F\left(x_{i}, y_{j}\right)$ of the air velocity were generated by same described software in the item (5) and results processed in electronic spread sheet.

\section{RESULTS AND DISCUSSION}

\section{Air velocity in freezing chamber}

Due the great variability of the air velocity in the space, to have a consistent representation of the velocity profile, becomes necessary to make the velocity measure in a relatively great number of points along of the flow section. The magnitude variation of the air velocity observed in the different treatments is due only to the presence of the boxes with the product that act as obstacles increasing the air flow resistance in accordance with processed product amount.

Figure (2) shows the experimental results of the measured air velocities along of the chamber section describing the its variation as function of the position in the freezing chamber input section before the pass by the product having as coordinated $(\mathrm{y}(\mathrm{m}))$, the chamber section width and $(\mathrm{x}(\mathrm{m}))$ the section height. The velocities readings are related to the axle $(\mathrm{z}(\mathrm{m} / \mathrm{s}))$ in the coordinate system of the figures graphs. The graphs was relating the boxes processing containing packed samples of the product in polyethylene bags of 100 grams put inside of the boxes in 7, 5 and 3 layers arrays respectively.

The measures heterogeneity obtained by the instrument, can be attributed to the brusque changes in the direction of the air flux, due to presence of obstacles and plant accessories. It means that the air velocity varies quickly as time function. Its average value in determined location becomes of difficult measurement. In the attempt to reduce these difficulties, the experimental results had been adjusted through non-linear regression, using a software (TableCurve3D $\left.{ }^{(R)}\right)$. Figures (3), (4) and (5) show the distribution of the air velocity normal to the input section of the freezing chamber following this procedure for samples packed in polyethylene bags and conditioned in plastic boxes in arrays of 7, 5 and 3 layers and processing air temperature established to the $-25^{\circ} \mathrm{C}$ (level 2).

Regression method for the fits was the least squares non-linear chosen for providing the best correlation coefficient $\left(\mathrm{r}^{2}\right)$. The result of the fit is a surface curve for the air velocity as function of the 
coordinates established for the input section of the freezing chamber given by the equation (2), where $\mathrm{F}(\mathrm{x}, \mathrm{y})$ is the adjusted non linear function. Results of the variance analysis, for the models of the surface curves presented in Fig. (3), (4) and (5) and necessary parameters to evaluate the correlation degree between the observed responses and the predicted values by the adjusted model, can be gotten.

The usual significance test of the adjusted regression equation is the test of the null hypothesis that involves the calculation of the F-statistic. Comparing the value of the F-statistic with the tabled value, $\mathrm{F}_{\alpha, \mathrm{p}-1, \mathrm{~N}-\mathrm{p}}$ where $\mathrm{N}$ is the number of observations, $\mathrm{p}$ the number of adjusted parameters and $\alpha$, the level of significance. If the value of $F$ statistic exceeds the value of $\mathrm{F}_{\alpha, \mathrm{p}-1, \mathrm{~N}-\mathrm{p}}$ tabled, then it is inferred with the significance level that the variation accounted by the model is significantly bigger that the variation not explained.

In other words, how much bigger the value of F-statistic the fit is better. It is observed that practically all the calculated values of F-statistic for the fits of the curves shown in Fig. (3), (4) and (5) are very above of the $F$ tabled value, indicating that the equations are significant (Khuri and Cornell, 1996).

Another parameter presented in tables is the determination coefficient $\left(r^{2}\right)$. The $r^{2}$ value is a measure of the variation ratio of the air velocity values $\left(\mathrm{v}_{\mathrm{u}}\right)$ around the average explained by the adjusted model. In tables of variance analysis, the percentage of variation explained by the regression is about of 70 to $85 \%$, but this value does not have to be compared with $100 \%$ because of the contribution due to the pure error, that is a measure of the random error that affects responses (Barros Neto et al., 1996).

This must be compared with the explicable maximum value that percentile is given by $r^{2}$ explicable in tables above. Despite the values Fstatistic in tables indicating a highly significant regression, in some cases the evidence of the fit lack exists and can be noted by the high value of specific $\mathrm{F}$ for the fit lack. The fit lack depends on the model and will be bigger when the estimates for a level to move more away from the average values of the responses determined in this level.
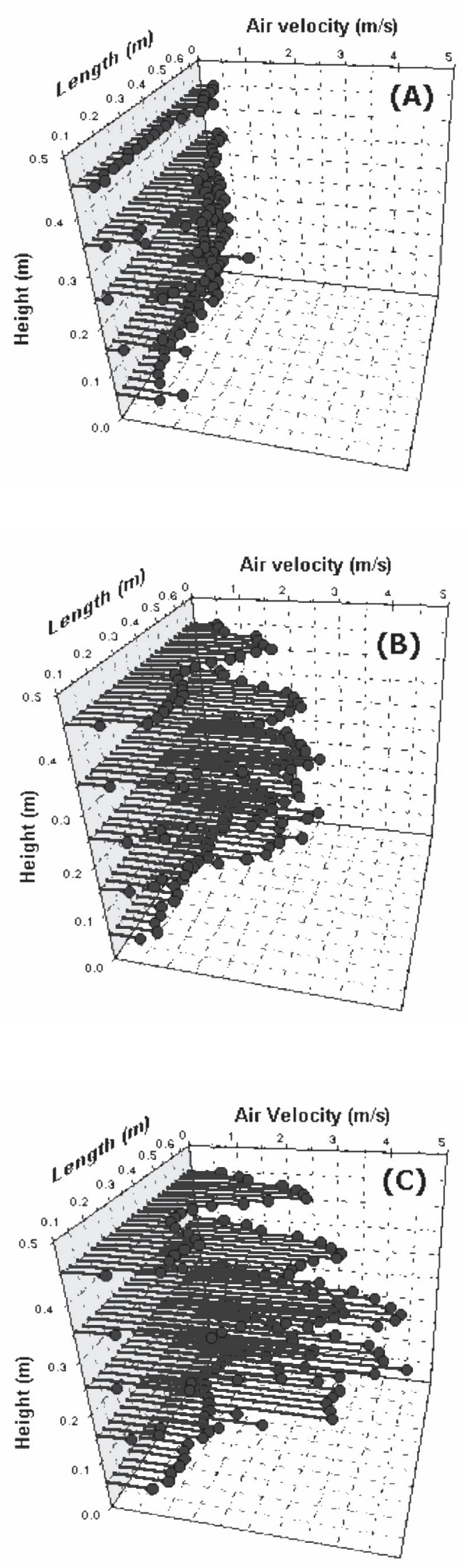

Figure 2. Experimental results of the air velocities along of the input section of the freezing chamber for arrays of (A) 7, (B) 5 and (C) 3 layers of samples and air temperature of $\left(\operatorname{Tar}=-25^{\circ} \mathrm{C}\right)$. 


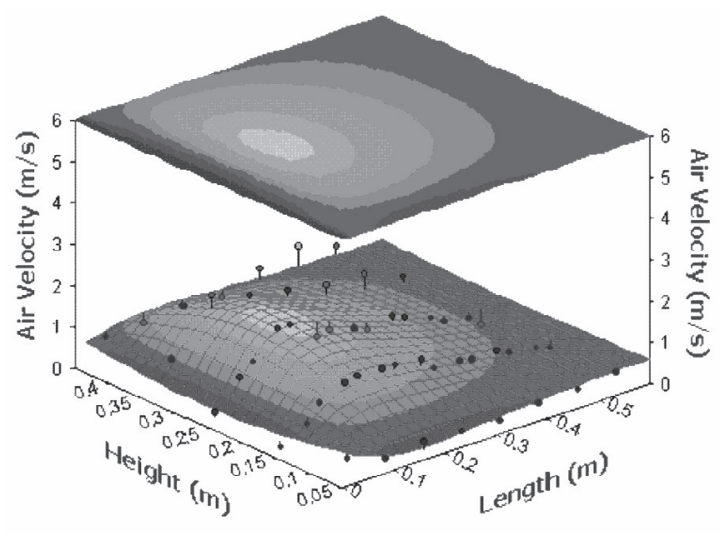

Figure 3. Distribution of the air velocity adjusted by non-linear regression in the input section of the freezing chamber for polyethylene bags inside of boxes in arrays of 7 layers and air temperature of $25^{\circ} \mathrm{C}$.

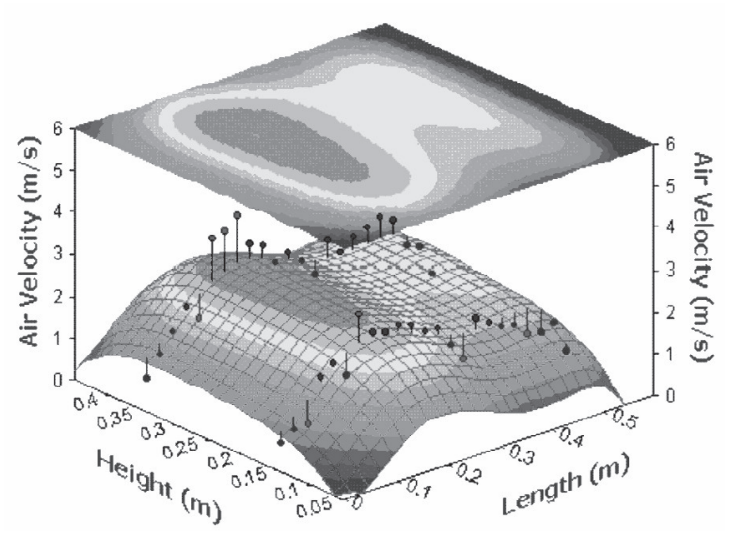

Figure 4. Distribution of the air velocity adjusted by non-linear regression in the input section of the freezing chamber for polyethylene bags inside of boxes in arrays of 5 layers and air temperature of $25^{\circ} \mathrm{C}$.

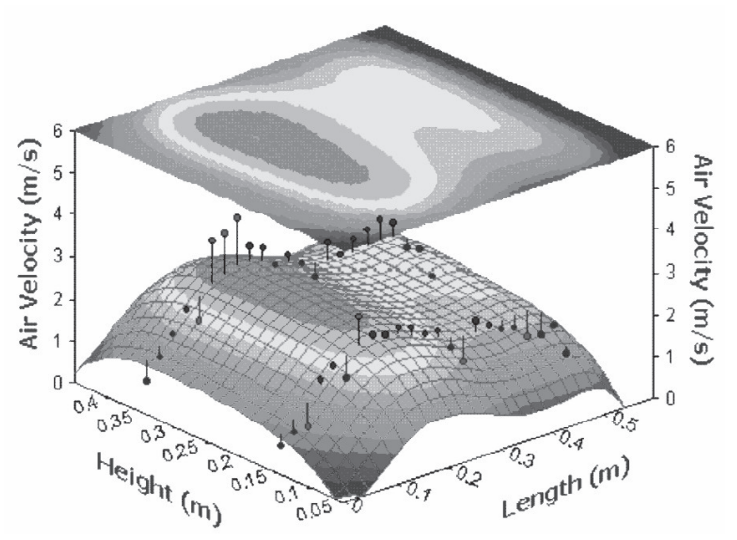

Figure 5. Distribution of the air velocity adjusted by non-linear regression in the input section of the freezing chamber for polyethylene bags inside of boxes in arrays of 3 layers and air temperature of $25^{\circ} \mathrm{C}$.
Another form to evaluate the fit quality that ould be used as second reason for the model acceptance, would be the residuals graph analysis. Fig. (6) shows the graphs of the residuals relative to experiments with 7,5 and 3 layers of product for models shown in Fig. (3), (4) and (5). The residuals are defined by the difference between the real response values observed and those predicted values for these responses using the adjusted model. The residuals left by the model must present a constant variance and random fluctuations around the plan that passes by the point zero (Fig. 6).
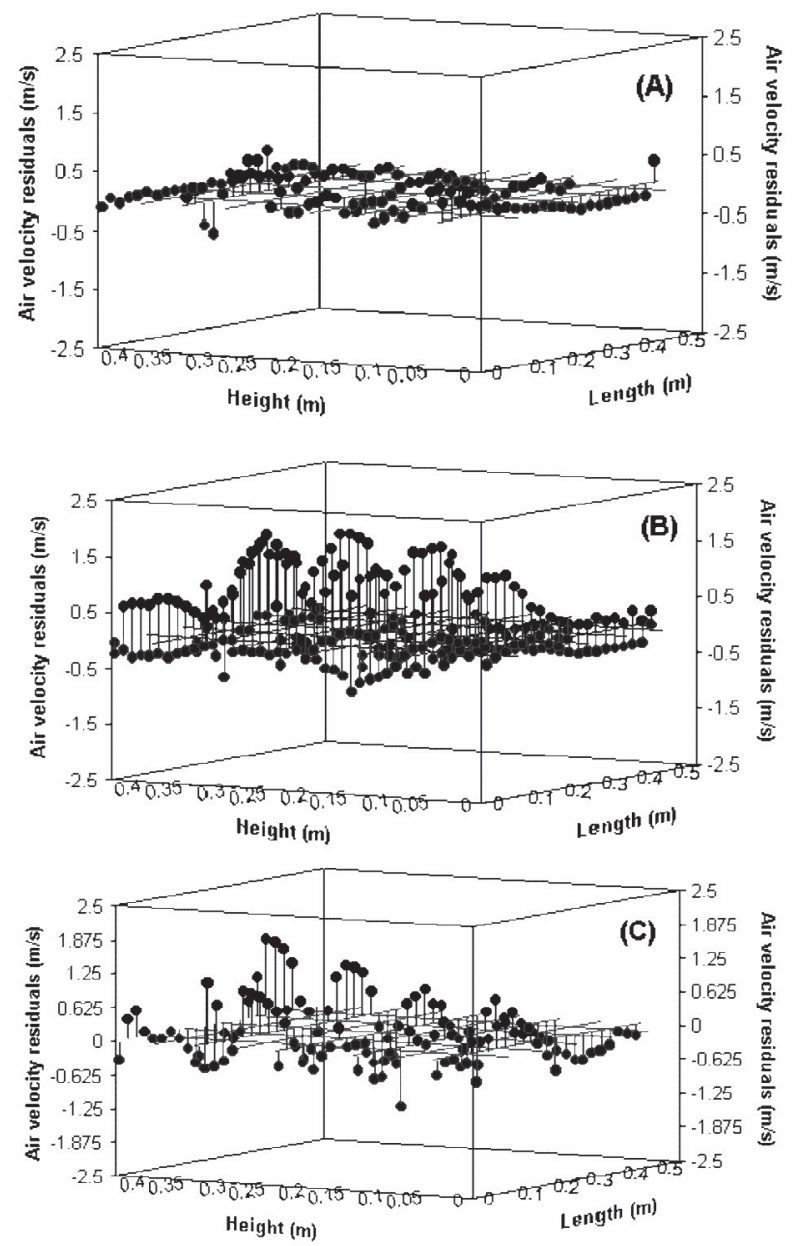

Figure 6. Residuals graphs for the models of the adjusted air velocity in experiments with boxes with arrays of (A) 7, (B) 5 and (C) 3 product layers.

With relation to the magnitude of the velocity vectors that describe the distribution of air flow, a considerable difference is verified visually when it is observed in the graphs of Fig. (3), (4) and (5). The variation is only caused by the processed amount of product that offers greater or minor resistance to the air flow in the chamber. It cannot affirm regarding a trend to these amounts. 
Therefore the assays of 7 layers possess a lesser dispersion of residuals, however the assays of 3 layers do not possess the biggest dispersion. What it can deduce is that in the arrays of 7 layers there are not great free spaces for the air flow and the air is forced to pass between the packages that offer resistance to the air flow in all the chamber section. The input profile becomes more uniform and the residual graphs for this array type (Fig. 7) practically presents a constant variance.

\section{Calculation of the air flow rate in the input section of the freezing chamber}

The air flow rate in the freezing chamber was determined following two procedures: (i) traditional procedure that consists of measuring the local velocity in some points of the flow section and estimating the average velocity by simple arithmetic mean, and thus, to evaluate the volumetric rate by the product of the average velocity by total area of the flow section, and, (ii) method, by bidimensional numerical integration through the determination of the volumetric rate under the adjusted response surface of the air velocity described in the previous section.

Table 3 shows the average values obtained using the two methodologies for the determination of the volumetric rate during the experiments of samples freezing packed in polyethylene bags in boxes with arrays of 7,5 and 3 layers and temperatures of air around $-20^{\circ} \mathrm{C},-25^{\circ} \mathrm{C}$ and $-30^{\circ} \mathrm{C}$. The last right column show comparative data between the two methods evaluated. The table also shows the total average amount of processed product in the three boxes in each experimental assay.

Table 3. Average values of the total mass $(\mathrm{kg})$ of product processed in different temperatures and of the air flow rate $\left(\mathrm{m}^{3} / \mathrm{s}\right)$ in the chamber section using experimental mean and numerical integration.

\begin{tabular}{|c|c|c|c|c|c|}
\hline \multicolumn{3}{|c|}{ Product amount } & \multicolumn{3}{c|}{$\begin{array}{c}\text { Methods of determination of the } \\
\text { air flow rate }\left(\mathrm{m}^{3} / \mathrm{s}\right)\end{array}$} \\
\hline \multirow{2}{*}{$\mathrm{T}\left({ }^{\circ} \mathrm{C}\right)$} & Layers & $\begin{array}{c}\text { Mass } \\
(\mathrm{kg})\end{array}$ & $\begin{array}{c}\text { Experim. } \\
\text { mean }\end{array}$ & $\begin{array}{c}\text { Numeric } \\
\text { integ. }\end{array}$ & $\begin{array}{c}\text { Relative } \\
\text { diff. }(\%)\end{array}$ \\
\hline \multirow{3}{*}{-20} & 7 & 56.769 & 0.1701 & 0.1914 & 11.14 \\
\cline { 2 - 6 } & 5 & 41.729 & 0.3454 & 0.3941 & 12.35 \\
\cline { 2 - 6 } & 3 & 26.830 & 0.5195 & 0.5959 & 12.82 \\
\hline \multirow{3}{*}{-25} & 7 & 56.809 & 0.1995 & 0.2220 & 10.15 \\
\cline { 2 - 6 } & 5 & 41.930 & 0.4068 & 0.4564 & 10.85 \\
\cline { 2 - 6 } & 3 & 26.984 & 0.5779 & 0.6520 & 7.41 \\
\hline \multirow{3}{*}{-30} & 7 & 57.008 & 0.2215 & 0.2137 & -3.64 \\
\cline { 2 - 6 } & 5 & 41.719 & 0.3696 & 0.4258 & 13.19 \\
\cline { 2 - 6 } & 3 & 27.157 & 0.4475 & 0.5060 & 11.55 \\
\hline
\end{tabular}

*Values obtained by the average of nine replications.
Table 3 shows in first instant that exists a considerable difference between the two treatment techniques of the observed velocity data. The used technique to describe the air flow by numerical integration presents the results with a difference in average $10 \%$ upper in relation to the results obtained by the traditional procedure. A difference around $10 \%$ for a parameter that describes this dimension type can provide a error accumulation sequence, leading to the not conclusive results in the finish of the process. In heat transfer calculations, depending on the conditions, demands a very great processing time. The determination of the superficial heat transfer coefficients is extremely dependent of the specifications and state of located flow, and the estimates of the heat load of the product depend directly on the air flow rate responsible by the heat withdrawal of the product during the freezing process.

\section{Effect of the product amount on the air flow rate in the freezing chamber}

Figure (7) shows the percentile reduction $(\Delta \mathrm{R} \%)$ of the air flow rate in the freezing chamber caused by the increase of the processed product amount (number of layers) considering the same fan rotation.

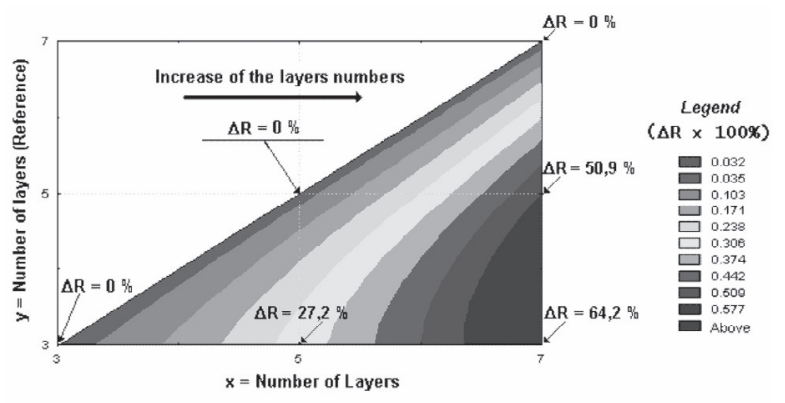

Figure 7. Percentile reduction of the air volumetric flow rate $(\Delta \mathrm{R} \%)$ in the freezing chamber caused by the increase of the product layers numbers.

The biggest values for the measures of the volumetric rate were obtained for experiments with arrays of 3 layers of product in the boxes of the piling up. Taking these values as reference, a reduction of 27.2 $\%$ in the volumetric rate of the cooling air is observed from Fig. (7) when the number of layers of the product is increased of 3 for 5 . When the increase is of 3 for 7 layers, the reduction of the air volumetric rate passing by the product reaches values around $64 \%$. If the volumetric rate measured for the arrays of 5 layers are taken as reference, the reduction of the air volumetric rate for an increase of 5 for 7 layers is about $51 \%$. These 
values can be justified in terms of the reduction of the free area for the air flow $\left(\Delta \mathrm{A}_{\mathrm{E}} \%\right)$.

The available area for the air flow $\left(\mathrm{A}_{\mathrm{E}}\right)$ is given by the difference between the total area $\left(\mathrm{A}_{\text {Total }}\right.$ of the normal section to the air flow direction calculated from the boxes dimensions and the area total of the arrays $\left(\mathrm{A}_{\text {array }}\right)$ that depends, on the layers numbers of the product processed inside of the boxes and, the individual samples dimensions (polyethylene bags - 100g) (equation 1).

Figure (8) shows the correlation between the values determined by the percentile reduction of the air volumetric rate $(\Delta \mathrm{R} \%)$ and the reduction of the available free area for the air flow $\left(\Delta \mathrm{A}_{\mathrm{E}} \%\right)$. The reduction of the volumetric rate caused by the increase of the product amount in the boxes is directly proportional to the reduction of the free area for the air flow.

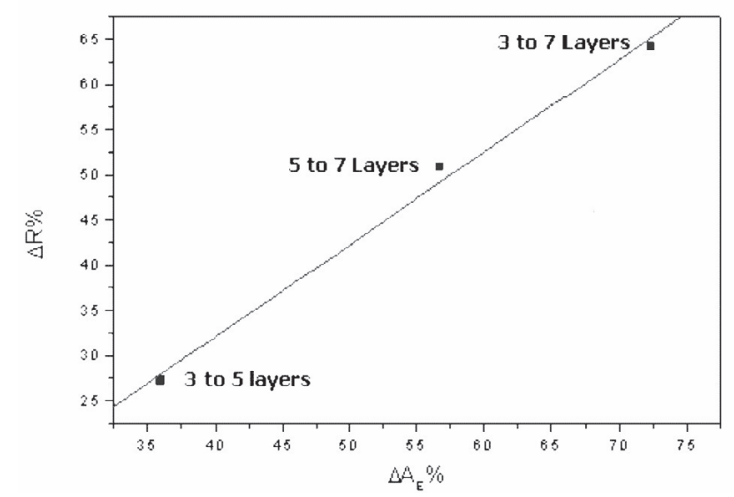

Figure 8. Correlation between the reduction of the air volumetric flow rate $(\Delta \mathrm{R} \%)$ and the reduction of the free area for the flow $\left(\Delta \mathrm{A}_{\mathrm{E}} \%\right)$.

\section{CONCLUSIONS}

The numerical integration method of the adjusted function of the velocity presented as alternative technique to the traditional procedure for the evaluation of the measures of the air velocity in the freezing chamber and for the description of the physical phenomenon of the air flow. The technique promotes a scanning of the measures values of the air velocity for all the flow section taking in account the presence of located flow, allows a estimate of the air volumetric rate by means of mathematical treatments and makes possible the detection and visualization of defects, phenomena and inherent problems of the flow by simple statistical methods as variance analysis, parameters of correlation of the fits and residuals analysis. The technique used to describe the flow by numerical integration present the results with a difference in average of $10 \%$ upper in relation to the results obtained by the traditional procedure.
The method presents as only inconvenience the time expense in the acquisition of the air velocity measures, that could be resolved and be realized with more information and greater accuracy by means of automation and probes communicating to the data acquisition systems. The space distribution of the gotten points is enough for analysis and detection of located flow. For the same operational conditions of the fan, the results for arrays of 7 layers had presented a reduction of $62 \%$ in the air volumetric rate in relation to the arrays of 3 layers and $50.9 \%$ in relation to the arrays of 5 layers. These data were proportional to the reduction of the free area for the air flow.

\section{ACKNOWLEDGEMENTS}

To Prof. Lincoln de Camargo Neves Filho and to $\mathrm{CNPq}$ (Conselho Nacional de Desenvolvimento Cientifico e Tecnológico) for financially supporting this study.

\section{REFERENCES}

Barros Neto, B., Scarminio, I. S. and Bruns, R. E., 1996, Planejamento e Otimização de Experimentos. $2^{\text {a }}$ Edição, Editora da UNICAMP. (in Portuguese)

Earle, R. L., 1985, Freezing of Foods: An Overview Food Engineering and Process Applications. Proceedings of the Fourth International Congress on Engineering and Food, Alberta, Canada, Vol. 2, pp. 3-20.

Hoerl, A. E., Nashed, M. Z., McKetta, J. J. and Silberberg, I. H., 1984, Mathematics. (eds.) Perry, H. P. and Green, D. Perry's Chemical Engineer's Handbook. Section 2, 6 a edition, McGraw-Hill, Inc.

Khuri, A. I. and Cornell, J. A., 1996, Response Surfaces - Designs and Analyses. 2nd Edition, Marcel Dekker, Inc.

Mirade, P. S. and Daudin, J. D., 1998, A New Experimental Method for Visualizing Air Flow in Large Food Plants, Journal of Food Enginnering, Vol. 36, pp. 31-49.

Ower, E. and Pankhurst, R. C., 1977, The Measurement ofAir flow-Methods ofFlow Measurement Based upon Rates of Cooling of Hot Bodies. Pergamon Press, England.

Peyrin, F., Kondjoyan,A. and Daudin, J. D., 1995, Analyse des Dificultés de Mesure de la Vitesse de l'air dans les Industries Agro-alimentaires, Industries Agroalimentaires et Agricoles, Vol. 112, №.10, pp. 728-735.

TSI Incorporated, 1997, Converting Standard Velocity to Actual Velocity. Industrial Test Instruments Application. http://www.tsi.com/iti/homepage/applenote/ ti-109.htm. 